\title{
INFLUÊNCIA DE DETERMINANTES AMBIENTAIS NA VEGETAÇÃO DA CAATINGA
}

\author{
Kionara Sarabella Turíbio e Silva ${ }^{1}$ \\ Adriana Monteiro Almeida ${ }^{2}$ \\ Thiago Sanna Freire Silva ${ }^{3}$
}

\section{RESUMO}

O bioma Caatinga é composto por florestas sazonalmente secas e vegetação arbustivoespinhosa e tem como característica climática a precipitação concentrada em poucos meses do ano. Como adaptação ao clima semiárido, a vegetação desenvolve folhas rapidamente na época chuvosa e as perde na época seca. Para analisar a influência de variáveis climáticas na dinâmica da vegetação, o presente estudo fez uso de técnicas de sensoriamento remoto e se utilizou de imagens EVI do sensor MODIS ao longo do ano de 2010. A precipitação acumulada anual e a temperatura média anual explicaram $40 \%$ da intensidade da vegetação $\left(\mathrm{R}^{2}=0,401 ; \mathrm{p}<0,05 ; \mathrm{n}=27\right)$. A presença e a intensidade da vegetação podem responder a diversos fatores, em virtude da sua alta heterogeneidade espacial e temporal, no entanto nesse estudo foram avaliadas a temperatura média e a pluviosidade acumulada que explicam grande parte da intensidade da vegetação.

Palavras-chaves: Moderate-Resolution Imaging Spectroradiometer (MODIS), EVI (Enhanced Vegetation Index), semiárido, precipitação.

\section{INFLUENCE OF ENVIRONMENTAL DETERMINANTS IN CAATINGA VEGETATION}

\begin{abstract}
The Caatinga biome is composed of seasonally dry forests and thorny shrub vegetation, subject to an irregular rainfall regime. As a consequence, vegetation develops leaves rapidly at the onset of the rainy season, losing them in the dry season, as adaptation to the semi-arid climate. To analyze the influence of temperature and precipitation patterns on Caatinga vegetation dynamics, this study used EVI images from the MODIS satellite sensor acquired through the year 2010. Both total annual precipitation and average temperature explained $40 \%$ of vegetation intensity ( $\mathrm{R} 2=0,401 ; \mathrm{p}<0,05 ; \mathrm{n}=27)$. We show that vegetation intensity respond to precipitation regimes and temperature, but other environmental factors must also influence vegetative phenology in the Caatinga, demonstrating the complexity and dynamism of such system.
\end{abstract}

\footnotetext{
${ }^{1}$ Mestre em Ecologia pela Universidade Federal do Rio Grande do Norte. E-mail: kionara@ @otmail.com.

2 Professora do Departamento de Ecologia e do Programa de Pós-Graduação e Pesquisa em Ecologia da Universidade Federal do Rio Grande do Norte. E-mail: adrianamda@gmail.com.

${ }^{3}$ Professor do Departamento de Geografia - Instituto de Geociências e Ciências Exatas (IGCE) UNESP Campus de Rio Claro/SP. Docente permanente do Programa de Pós Graduação em Geografia (IGCE/UNESP) e do Programa de Pós-Graduação em Ecologia e Biodiversidade (IB/UNESP). E-mail: thiago@ltid.inpe.br.
}

Sociedade e Território - Natal. Vol. 29, N. 1, p. 183 - 198. Jan./Jun. de 2017 
Keywords: Moderate-Resolution Imaging Spectroradiometer (MODIS), EVI (Enhanced Vegetation Index), remote sensing, rainfall.

\section{INFLUENCIA DE DETERMINANTES AMBIENTALES EN LA VEGETACIÓN DE LA CAATINGA}

\section{RESUMEN}

El bioma Caatinga se compone de una vegetación arbustiva-espinosa estacionalmente seca y tiene como característica climática precipitaciones concentradas en pocos meses del año. Como adaptación al clima semiárido, la vegetación desarrolla hojas en la época lluviosa y las pierde en la época seca. Para analizar la influencia de variables climáticas en la dinámica de la vegetación, el presente estudio utilizó técnicas de sensoriamento remoto a partir de imágenes de EVI del sensor MODIS obtenidas a lo largo del 2010. La precipitación anual acumulada y la temperatura anual media explicaron $40 \%$ de la intensidad de la vegetación (R2 $=0.401$, $\mathrm{p}<0.05, \mathrm{n}=27$ ). La presencia y la intensidad de la vegetación puede responder a diversos factores, en virtud de su alta heterogeneidad espacial y temporal, no obstante, en este estudio evaluamos la temperatura media y precipitación acumulada que explican gran parte de la intensidad de la vegetación.

Palabras claves: Moderate-Resolution Imaging Spectroradiometer (MODIS), EVI (Enhanced Vegetation Index), detección remota, precipitación.

\section{INTRODUÇÃO}

A Caatinga, composta por florestas sazonalmente secas em virtude de um regime de chuvas irregular e vegetação arbustivo-espinhosa (LEAL et al., 2005), ocupa uma área correspondente a, aproximadamente, 10\% do território nacional (IBGE, 2004). Apesar disso, poucas ações de proteção são desenvolvidas, e aproximadamente, $50 \%$ desse ambiente já se encontra degradado em virtude das atividades humanas, especialmente a pecuária, agricultura e o corte de madeira para lenha (MMA/IBAMA, 2010). Tais atividades resultam, entre outros problemas, em modificações na paisagem natural desse ecossistema.

O bioma Caatinga é um verdadeiro mosaico de diferentes tipos de vegetação gerados a partir de variações de grande escala como os padrões climáticos e orográficos, bem como os de pequena escala como os diferentes tipos de solo e características topográficas locais (SAMPAIO, 1995). Tal heterogeneidade espacial confere ao bioma alta diversidade biológica e inúmeros endemismos em relação a outras regiões áridas e semiáridas do mundo (LEAL et al., 2005).

A Caatinga ainda é um ambiente pouco estudado, especialmente na perspectiva do sensoriamento remoto. O imageamento por satélite disponibiliza dados para analisar e 
monitorar os eventos fenológicos em diversas regiões do mundo (REED et al., 1994). Assim, o uso dessa técnica mostra-se bastante relevante, uma vez que permite uma eficiente obtenção de dados em uma área com uma ampla extensão geográfica e pouca informação de campo, no caso analisado a Caatinga. Por isso, é uma importante fonte de informação que possibilita um melhor entendimento do funcionamento e dos processos ecossistêmicos, bem como dos padrões de degradação que precisam ser detectados para adoção de medidas de controle e até mesmo de restauração.

O déficit hídrico ao longo do ano na região influencia fortemente a vegetação de tal forma que a sua intensidade, variável no tempo e no espaço, proporciona a variação da sua fisionomia e flora (SAMPAIO, 1995). Observações a partir do sensoriamento remoto das variações na dinâmica da vegetação (variações na biomassa verde) têm sido amplamente utilizadas para identificação de seus padrões e suas relações com determinantes ambientais (JENERETTE et al., 2010).

A precipitação no bioma Caatinga diminui no sentido bordas-interior, visto que as massas de ar perdem umidade à medida que penetram na região. Essas frentes entram no continente e são modificadas pela diferença de altitude que, apesar de pequena (picos mais altos entre 400 e $500 \mathrm{~m}$, podendo alcançar $1000 \mathrm{~m}$ em locais específicos), cria um microclima mais úmido nos locais onde o relevo intercepta essas frentes, e mais seco a sotavento (SAMPAIO, 1995). Apesar do reconhecimento universal da relação bidirecional entre vegetação e regime de chuvas, é preciso compreender como essa interação ocorre no bioma Caatinga e quais outros fatores ambientais são responsáveis pela sua heterogeneidade espacial e temporal.

Diante do exposto, este trabalho tem como objetivo investigar o grau de influência da precipitação e da temperatura na dinâmica da vegetação, através do uso das técnicas do sensoriamento remoto. Acredita-se que a vegetação seja influenciada pelo regime de precipitação, porém outros fatores podem influenciar na sua dinâmica.

\section{MATERIAL E MÉTODOS}

\section{Área de estudo}

$\mathrm{O}$ bioma Caatinga estende-se entre $35^{\circ} \mathrm{W}$ a $42^{\circ} \mathrm{W}$ e $3^{\circ} \mathrm{S}$ a $16^{\circ} \mathrm{S}$, com uma área aproximada de $845 \mathrm{mil} \mathrm{km} \mathrm{km}^{2}$, correspondente a 10\% do território nacional (IBGE, 2017). Está localizado no nordeste Brasileiro e ocupa os estados da Bahia, Ceará, Paraíba, Pernambuco, 
Piauí, Rio Grande do Norte, Sergipe, Alagoas, Maranhão e norte de Minas Gerais (Figura 1).

Figura 1: Delimitação do bioma Caatinga, de acordo com o Mapa de Biomas do Brasil (IBGE, 2004) e a localização das estações meteorológicas usadas no estudo.

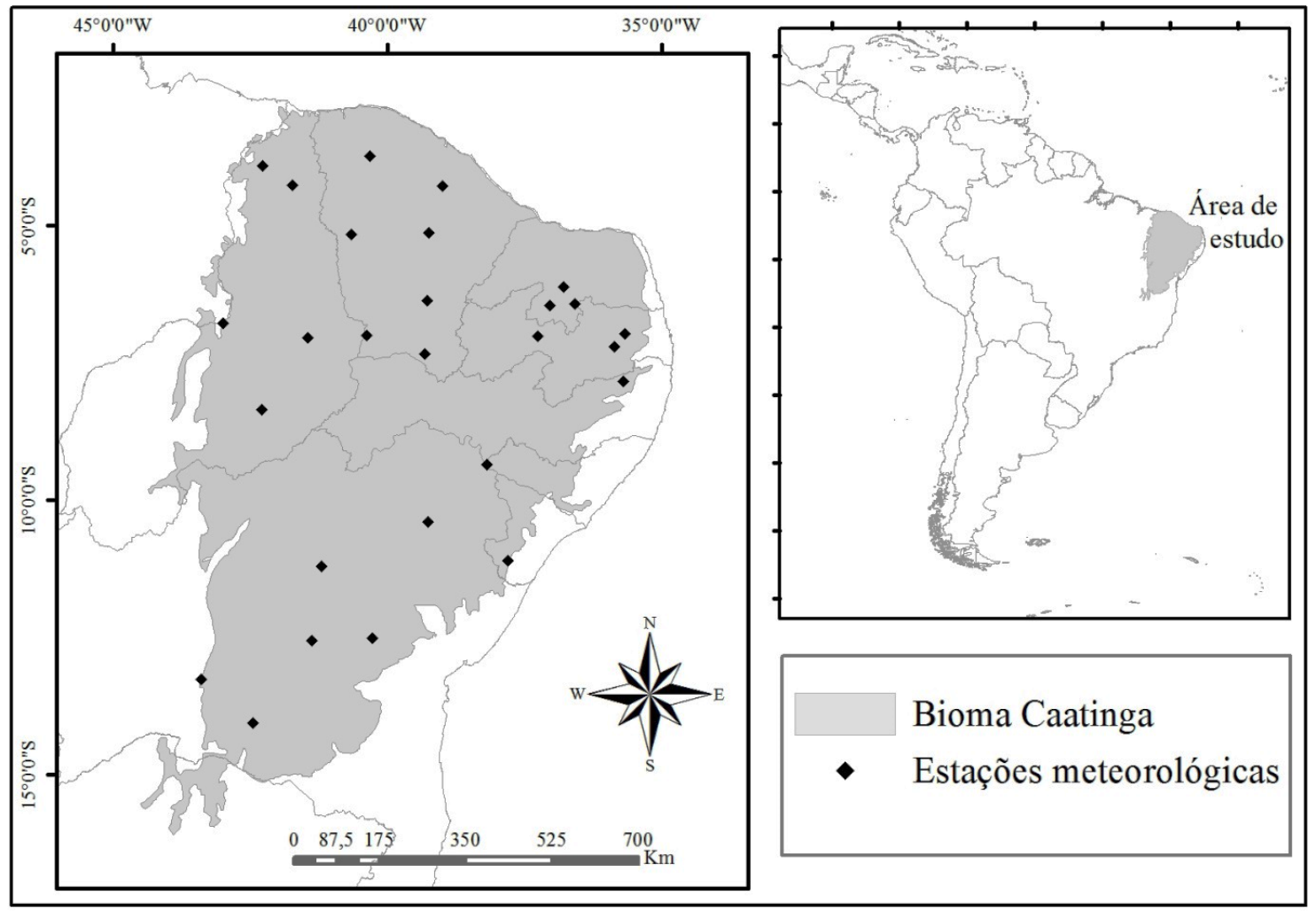

Fonte: IBGE, 2004.

A Caatinga apresenta em sua composição uma combinação de plantas decíduas e herbáceas anuais, com associações de plantas e estruturas florísticas complexas com diferentes fisionomias como plantas xerófitas, arbustivas espinhosas, árvores decíduas, cactos e bromeliáceas (BARBOSA et al., 2006).

As espécies de Cactaceae dão fisionomia típica a certas áreas da Caatinga. Os gêneros mais representativos da família Anacardiaceae são Schinopsis, Astronium e Spondias que possuem importância econômica na produção de madeira e, neste último, com a espécie Spondias tuberosa Arruda ainda há a produção de frutos. No estrato arbóreo têm-se: Burseraceae (Bursera leptophloeos Mart.), Celastraceae (Maytenus rígida Mart. e Fraunhoffera multiflora Mart.), Bignoniaceae (Tabebuia aurea (Silva Manso) Benth. \& Hook.f. ex S.Moore, Handroanthus impetiginosus (Mart. ex DC.) Mattos), Euphorbiaceae (Cnidoscolus phyllacanthus (Müll. Arg.) Pax \& L. Hoffm.). Dentre as rasteiras, as Bromeliaceae são bastante comuns e presentes no bioma Caatinga (Andrade-Lima, 1981).

O clima é do tipo BSh, segundo a classificação climática de Köepen, resultando em 
uma cobertura vegetal predominantemente caducifólia, perdendo suas folhas durante os períodos de seca como forma de adaptação ao clima extremo (ANDRADE-LIMA, 1981).

\section{Sensor MODIS}

O sensor Moderate-Resolution Imaging Spectroradiometer (MODIS) é o principal instrumento das plataformas Terra e Aqua, integrantes do sistema Earth Observing System (EOS) da NASA. O mesmo foi projetado para a realização de estudos científicos multidisciplinares, cujos objetivos são avaliar o crescente impacto da atividade antrópica sobre o planeta e monitorar as mudanças na superfície e na atmosfera terrestre. Uma de suas principais características é a disponibilização de imagens na forma de produtos específicos, com alto nível de pré-processamento, facilitando assim o seu uso pela comunidade científica (SOARES et al., 2007).

O sensor MODIS foi desenvolvido para proporcionar um melhor monitoramento da terra e oceano, além de desenvolver pesquisas atmosféricas cobrindo o planeta a cada dois dias. Possui 36 bandas contidas no intervalo de 0,4 a 14,4 $\mu \mathrm{m}$ do espectro eletromagnético, alta sensibilidade radiométrica (12 bits) e resolução espacial de $250 \mathrm{~m}$ (bandas 1 e 2), $500 \mathrm{~m}$ (bandas 3 a 7) e $1 \mathrm{~km}$ (bandas 8 a 36), cobrindo uma faixa imageada de $2.330 \mathrm{~km}$ (Barnes et al., 1998).

Dentre os produtos derivados das imagens MODIS, têm-se o produto MOD-13, que inclui índices de vegetação gerados a intervalos de 16 dias. Os índices de vegetação são valores calculados através da operação entre duas ou mais bandas espectrais, com o intuito de realçar as propriedades da vegetação e minimizar variações de iluminação e do terreno, facilitando a comparação temporal e espacial da distribuição, produtividade, atividade fotossintética, além das variações estruturais e fenológicas da cobertura vegetal (HUETE et al., 2002).

O produto MOD-13 inclui dois índices de vegetação: o Normalized Difference Vegetation Index (NDVI), e o Enhanced Vegetation Index (EVI). Ambos são produzidos usando-se, para cada pixel, o maior valor do índice observado nas imagens de reflectância diárias do sensor MODIS durante um período de 16 dias, para minimizar a presença de nuvens (ANDERSON; SHIMABUKURO, 2007). Os índices de vegetação do sensor MODIS são disponibilizados com uma resolução espacial de $250 \mathrm{~m}$, viabilizando estudos em escala regional com uma alta resolução temporal.

O índice EVI foi escolhido para o presente estudo por ser mais apropriado para o uso 
em regiões semiáridas, uma vez que foi desenvolvido para reduzir a sensibilidade do solo e os efeitos atmosféricos (HUETE et al., 2002; JOHN et al., 2008; OLIVEIRA et al., 2009; JENERETTE et al., 2010). A equação do índice EVI segue abaixo, em que $\rho N I R$ se refere ao valor de reflectância para infravermelho próximo, pred ao valor de reflectância para o vermelho, $\rho$ blue se refere ao valor de reflectância para o azul, L é o fator para ajuste do solo e C1, C2 são os coeficientes de ajuste para o efeito de aerossóis que usa a faixa do azul para corrigir a influência de aerossóis na faixa do vermelho (Huete et al., 2002).

$$
E V I=G \frac{\rho N I R-\text { pred }}{\rho N I R+C 1 \times \rho r e d-C 2 \times \rho b l u e+L}
$$

\section{Análise da influência da precipitação na dinâmica da vegetação}

Os dados de pluviosidade e temperatura foram obtidos a partir de 28 estações climáticas (Figura 1) para o ano de 2010 disponíveis no "Banco de Dados para Ensino e Pesquisa do Instituto Nacional de Meteorologia" (INMET/BDMEP).

Foram utilizadas quatro cenas do índice EVI, bem como as bandas do vermelho e do azul do sensor MODIS (cenas h13v9, h13v10, h14v9 e h14v10), produzidas a cada 16 dias para o ano de 2010. Essas imagens foram obtidas através do programa MODIS Reprojection Tool Web (NASA) com resolução espacial de 250 metros.

Em seguida, foram extraídos os valores de EVI na localização de cada uma das estações climáticas para análise da relação do verdor da vegetação com as variáveis ambientais pluviosidade e temperatura. Os procedimentos de extração dos valores de EVI por estação, assim como a criação de mapas foram realizados no programa ArcGIS 9.3 (ESRI, 2009).

De cada ponto com estação meteorológica usado no estudo, foi obtido o valor do EVI máximo ao longo do ano. Essa variável foi escolhida, pois a época da estação chuvosa varia em cada sub-região do bioma, não havendo, assim, um período de chuva fixo que contemple toda área de estudo e promova, em seguida, uma resposta na vegetação. Dessa forma, nas análises foram usados dados de precipitação acumulada anual, temperatura média anual e o maior valor de EVI.

Devido a possíveis erros de posicionamento, e a possível ocorrência de variações nos valores de EVI, optou-se por analisar o valor médio do pixel e de seus oito pixels adjacentes (totalizando nove pixels). Além disso, as 28 localizações das estações foram inspecionadas através de análise visual com o GOOGLE EARTH para garantir que os pixels selecionados Sociedade e Território - Natal. Vol. 29, N. 1, p. 183 - 198. Jan./Jun. de 2017 
correspondem a vegetação natural da Caatinga. Nos casos em que a estação não se encontrava em local com vegetação característica do bioma, foram selecionados os pixels mais próximos que correspondiam à Caatinga vegetada (com uma distância máxima de 4,5 km).

Em seguida, para cada imagem resultante, a área correspondente à Caatinga foi extraída a partir do arquivo vetorial do Mapa de Biomas do Brasil (IBGE, 2004). Após a delineação dos seus limites, as imagens foram visualizadas em composição colorida (RGB EVI-Red-Blue - falsa cor) e submetidas a um processo de classificação não supervisionada através do algoritmo K-médias, em que o número de classes é determinado pelo usuário e os agrupamentos são criados a partir da média dos valores de pixels mais próximos.

Durante a classificação, apenas três classes de cobertura foram especificadas: vegetação, água e solo. Esta última engloba todos os elementos que não forem água ou vegetação. O resultado final consistiu em uma série de mapas de vegetação. Todo o processamento foi realizado através do software ENVI 4.5 (SULSOFT, 2010).

Os 23 mapas de vegetação (imagens EVI-MODIS são geradas a cada 16 dias) foram utilizados para análise da variação da cobertura vegetal ao longo do ano de 2010, quantificando-se a área correspondente à classe vegetação em cada mapa, assim como identificando-se os períodos com maior e menor cobertura vegetal.

\section{Análise Estatística}

Para determinação do grau de influência da precipitação acumulada anual e temperatura média mensal nos valores de índice de vegetação, foram gerados modelos com esses parâmetros, através de análises de regressão simples e múltipla realizados no programa R (CHAMBERS, 1992). Foi utilizado o Critério de Informação de Akaike (AIC), que permite a seleção de modelos que melhor explicam a variação dos dados (Burnham; Anderson, 2004). Através da análise dos dados, foi preciso remover um dos pontos considerado outlier, localizado no Morro do Chapéu-BA.

A fim de se verificarem os requerimentos da análise de regressão, a normalidade dos dados foi testada através do teste de Shapiro-Wilk (1965).

\section{RESULTADOS}

A biomassa fotossinteticamente ativa na caatinga alcançou suas maiores extensões no período entre janeiro e maio de 2010, tendo seu maior valor no mês de abril, com 533.030 $\mathrm{km}^{2}$, correspondente a aproximadamente $63 \%$ da área de Caatinga. A partir de junho Sociedade e Território - Natal. Vol. 29, N. 1, p. 183 - 198. Jan./Jun. de 2017 
observou-se uma gradativa diminuição da cobertura até o mês de setembro, mês de menor valor, com $297.905 \mathrm{~km}^{2}$, representando cerca de $35 \%$ da área de Caatinga. A partir deste ponto, a cobertura vegetal aumentou até dezembro, mas sem superar os valores dos primeiros meses do ano (Figura 2).

Figura 2:Variação da área verde mapeada $\left(\mathrm{em}^{\mathrm{km}}{ }^{2}\right)$ ao longo do ano de 2010.

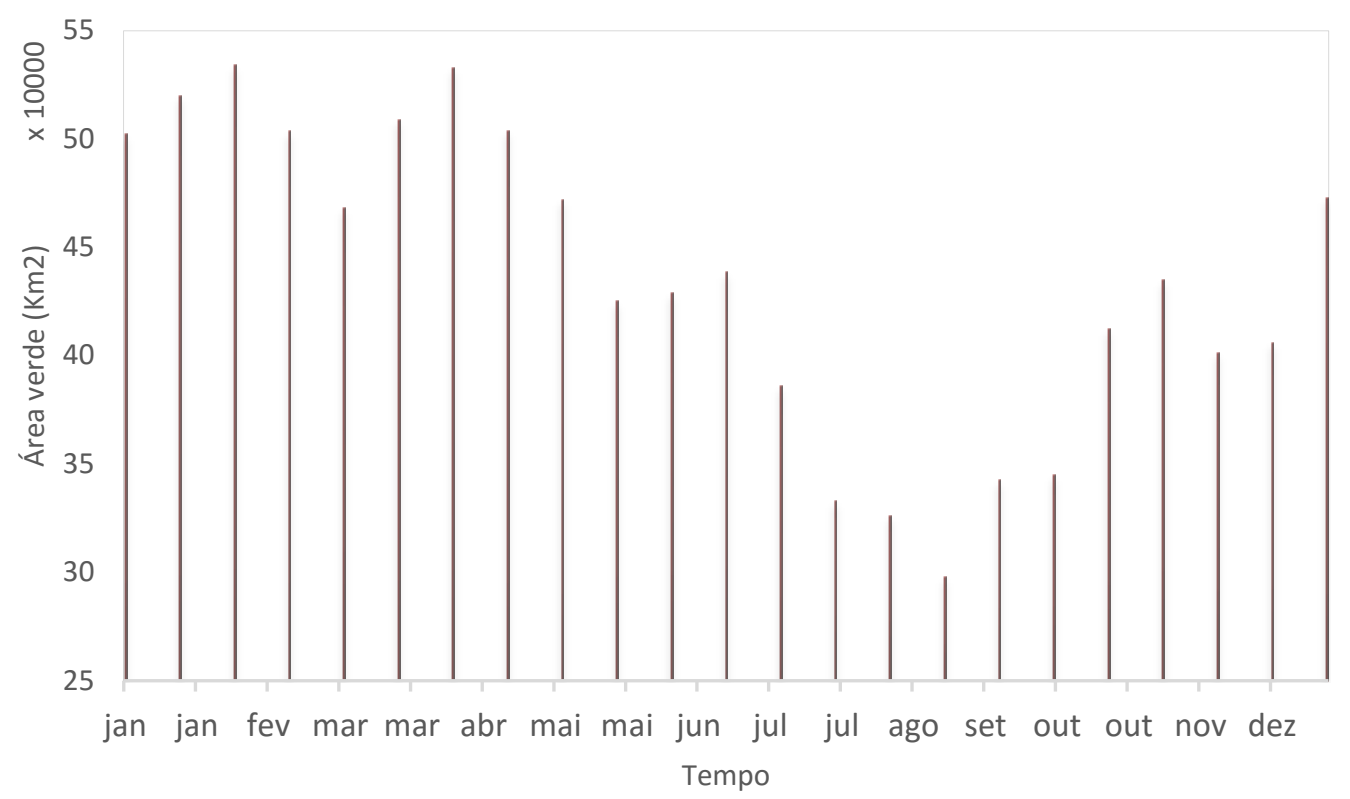

A redução de $44 \%\left(235.125 \mathrm{~km}^{2}\right)$ da cobertura vegetal entre a estação chuvosa (abril) e a seca (setembro), em um período aproximado de quatro meses, demonstra o dinamismo da paisagem da Caatinga (Figura 2).

Quando se trata de imagens advindas do sensoriamento remoto, uma das implicações é a presença de nuvens. É perceptível a sua presença mesmo naquelas advindas do sensor MODIS (Figura 3). Nas imagens classificadas (Figuras 4a e 4b), é possível visualizar a forte sazonalidade entre o período chuvoso e seco de 2010, com forte perda das folhas na estação seca. 
Figura 3: Imagens MODIS coloridas, na composição RGB EVI-Red-Blue - falsa cor (vegetação na cor vermelha), no período (A) chuvoso (abril) e no (B) seco (setembro), respectivamente, do ano de 2010 . É perceptível a presença de nuvens na estação chuvosa.

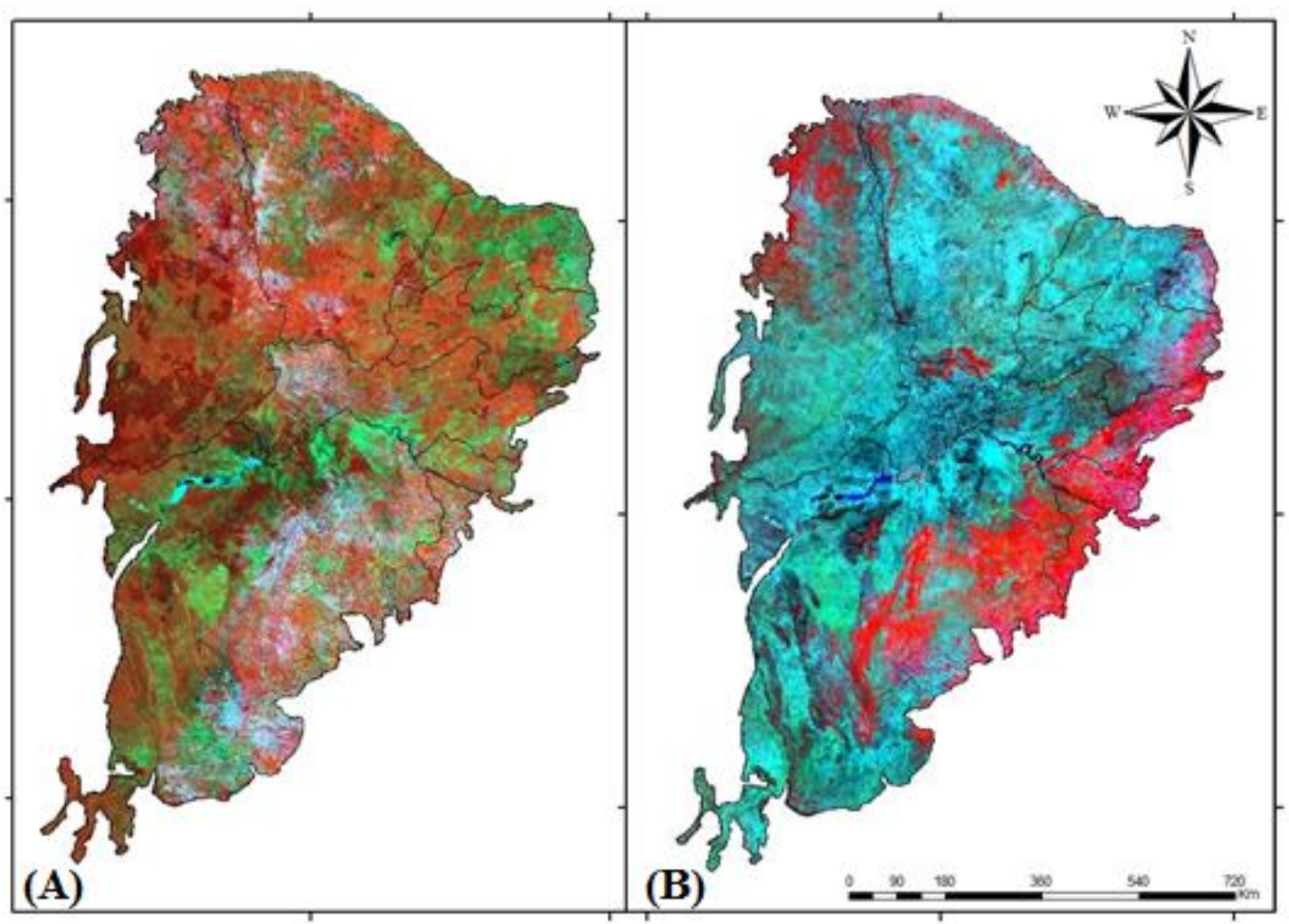

Figura 4: Imagens MODIS classificadas mostrando vegetação em verde, no período (A) chuvoso (abril) e no (B) seco (setembro), respectivamente, do ano de 201

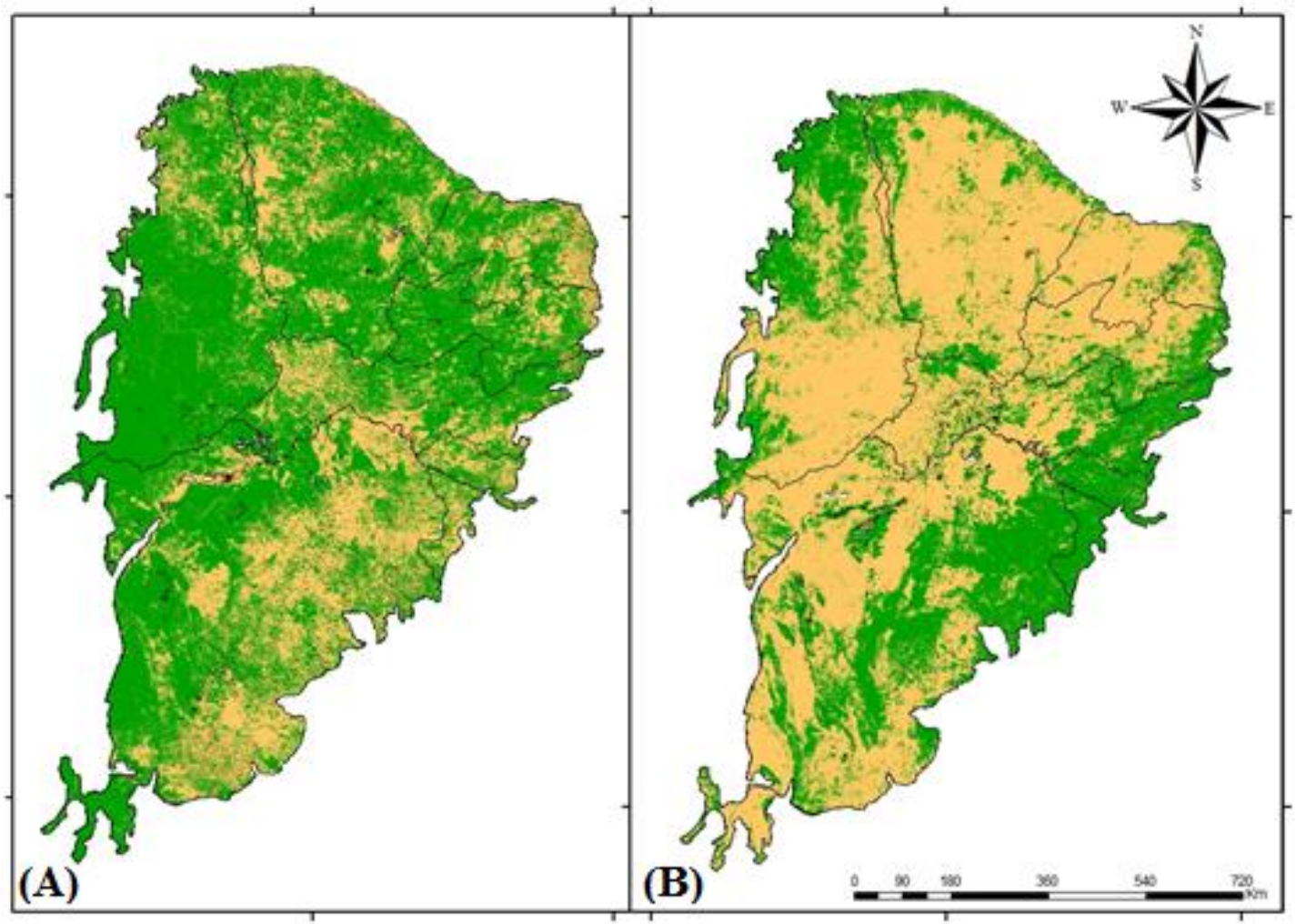

Sociedade e Território - Natal. Vol. 29, N. 1, p. 183 - 198. Jan./Jun. de 2017 
A região da Caatinga apresenta ainda uma grande heterogeneidade quanto à densidade e porte de sua vegetação. Para as imagens digitais nesse estudo, quanto mais clara a tonalidade do pixel, maior a intensidade do alvo que o representa, no caso a biomassa verde. No pico da estação chuvosa observam-se diversas tonalidades de cinza (vegetação) comprovando a variação fisionômica, além das modificações humanas presentes no bioma (Figura 5a e 5b).

Figura 5. Imagens EVI do sensor MODIS no período (A) chuvoso (abril) e (B) seco (setembro) no ano de 2010. As diferentes tonalidades de cinza demonstram a grande heterogeneidade espacial presente na Caatinga, com tons mais claros indicando maior biomassa verde.

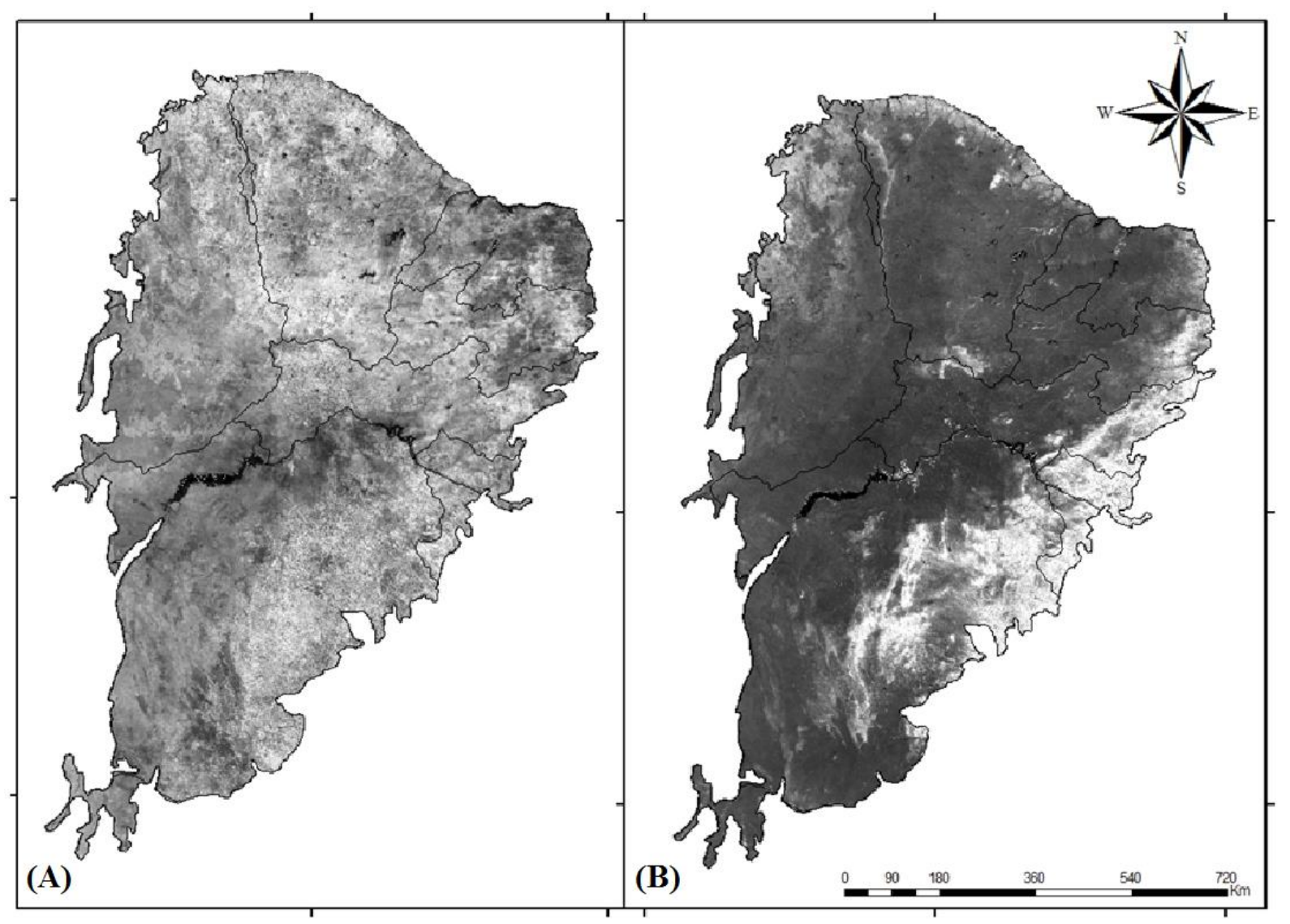

Os valores de precipitação acumulada anual variaram drasticamente entre os pontos amostrados, variando entre 440,6 mm no município de Crateús-CE e 1332,5 mm no município de Itabaianinha-SE (Tabela 1). 
Tabela 1: Valores de EVI máximo, precipitação acumulada anual e temperatura média anual para cada estação analisada.

\begin{tabular}{|c|c|c|c|}
\hline Estação & $\begin{array}{c}\text { EVI } \\
\text { máximo }\end{array}$ & $\begin{array}{c}\text { Precipitação } \\
\text { (mm) }\end{array}$ & $\begin{array}{c}\text { Temperatura } \\
\left({ }^{\circ} \mathrm{C}\right)\end{array}$ \\
\hline AREIA - PB & 0,6738 & 1020,4 & 22,75 \\
\hline BARBALHA - CE & 0,5845 & 1108 & 26,04 \\
\hline BOM JESUS DA LAPA - BA & 0,5948 & 729,7 & 26,47 \\
\hline CAETITE - BA & 0,5593 & 699,1 & 22,53 \\
\hline CAMPINA GRANDE - PB & 0,693 & 703,7 & 23,87 \\
\hline CAMPOS SALES - CE & 0,5169 & 813,5 & 25,07 \\
\hline CRATEUS - CE & 0,3961 & 440,6 & 28,42 \\
\hline CRUZETA - RN & 0,5702 & 740,6 & 27,65 \\
\hline ESPERANTINA - PI & 0,5758 & 1410,4 & 27,51 \\
\hline FLORANIA - RN & 0,6012 & 717,7 & 26,97 \\
\hline FLORIANO - PI & 0,4657 & 857,4 & 28,76 \\
\hline GUARAMIRANGA - CE & 0,6678 & 1075,1 & 21,61 \\
\hline IGUATU - CE & 0,569 & 854,1 & 27,82 \\
\hline ITABAIANINHA - SE & 0,7337 & 1332,5 & 24,79 \\
\hline ITABERABA - BA & 0,6805 & 722,8 & 25,26 \\
\hline ITUACU - BA & 0,483 & 664,4 & 24,58 \\
\hline LENCOIS - BA & 0,5989 & 883,6 & 24,25 \\
\hline MONTE SANTO - BA & 0,5815 & 861,6 & 24,09 \\
\hline MORRO DO CHAPEU - BA & 0,4368 & 827,5 & 20,91 \\
\hline PATOS - PB & 0,3805 & 516,4 & 27,70 \\
\hline PAULO AFONSO - BA & 0,6401 & 518,7 & 26,14 \\
\hline PICOS - PI & 0,4981 & 759 & 28,41 \\
\hline PIRIPIRI - PI & 0,6211 & 1365,5 & 28,03 \\
\hline QUIXERAMOBIM - CE & 0,6508 & 681,8 & 27,72 \\
\hline SAO JOAO DO PIAUI - PI & 0,5572 & 625,9 & 28,14 \\
\hline CAICO - RN & 0,4456 & 700,7 & 28,32 \\
\hline SOBRAL - CE & 0,5582 & 644,9 & 28,13 \\
\hline SURUBIM - PE & 0,581 & 733 & 24,47 \\
\hline
\end{tabular}

Com relação à investigação sobre a influência dos determinantes ambientais na vegetação do bioma Caatinga, o modelo selecionado através do Critério de Seleção de Akaike foi aquele que prediz a vegetação (índice de vegetação EVI) em função da pluviosidade e da temperatura (Tabela 2). 
Tabela 2: Seleção do modelo pelo Critério de Informação de Akaike (AIC).

\begin{tabular}{llll}
\hline Modelos & GL & $\Delta$ AIC & $\mathrm{R}^{2}$ \\
\hline EVI PLUVIOSIDADE+TEMPERATURA & 3 & 0 & 0,4012 \\
EVI TEMPERATURA & 3 & 3,57 & 0,2638 \\
EVI PLUVIOSIDADE & 4 & 5,45 & 0,2108
\end{tabular}

$\mathrm{GL}=$ Grau de liberdade; $\triangle \mathrm{AIC}=$ Delta do critério de informação de Akaike (do inglês Akaike's Information Criterion); R2= Coeficiente de determinação.

O resultado da análise de regressão múltipla do modelo selecionado está apresentado na tabela 3. Foi possível constatar a relação positiva e significativa entre a pluviosidade (coeficiente $=0,3771 ; p=0,0276$ ) e a cobertura vegetal, enquanto que a temperatura teve uma relação negativa e significativa (coeficiente $=-0,4439 ; \mathrm{p}=0,0109$ ). Os fatores ambientais analisados no modelo selecionado explicaram $40 \%$ da variação da cobertura vegetal $\left(\mathrm{R}^{2}=\right.$ $0,4012 ; \mathrm{p}=0,0021)$.

Tabela 3: Análise de regressão múltipla entre o índice de vegetação EVI e as variáveis ambientais.

\begin{tabular}{lllll}
\hline & Coef. & Erro padrão & t & P \\
\hline Constante & 0,0000 & 0,1550 & 0,000 & \\
Pluviosidade acumulada anual & 0,3771 & 0,1607 & 2,346 & 0,0276 \\
Temperatura média anual & $-0,4439$ & 0,1607 & $-2,762$ & 0,0109 \\
\hline Variável dependente: EVI máximo anual & & $\mathrm{p}: 0,0021$ & $\mathrm{R}$ : 0,4012 \\
\hline
\end{tabular}

Coef.= Valores dos coeficientes das variáveis preditoras; $\mathrm{t}=$ Valores do teste $\mathrm{t} ; \mathrm{P}=$ Significância do teste $\mathrm{t}$.

\section{DISCUSSÃO}

A área vegetada na Caatinga variou de forma acentuada no ano do estudo, apresentando um decréscimo de $44 \%$ de área com biomassa verde (Figuras 2 e 4). A explicação ecológica para a mudança rápida da vegetação em relação ao clima é a presença de diversas adaptações evolutivas que permitem a sobrevivência das plantas. Dentre elas, tem-se a perda das folhas da maioria das plantas durante a estação seca para economia de água. Outra forma de adaptação é a liberação das sementes de herbáceas anuais em um período mais úmido e favorável ao seu desenvolvimento. E ainda, há a presença de plantas de metabolismo CAM (em português significa metabolismo do ácido das crassuláceas) que permite a conservação hídrica da planta, uma vez que há trocas gasosas somente durante a noite, para evitar a perda de água através da evapotranspiração (SAMPAIO, 1995).

Apesar da altitude não entrar como parâmetro na análise do modelo em virtude da sua alta colinearidade com a variável temperatura, percebe-se que algumas outras áreas que Sociedade e Território - Natal. Vol. 29, N. 1, p. 183 - 198. Jan./Jun. de 2017 
possuem uma cobertura vegetal marcante encontram-se nas altitudes maiores (comparar Figura $4 \mathrm{~b}$ e Figura 6). Tal fato é provavelmente causado em virtude das chuvas orográficas que possibilitam um clima mais úmido ao longo do ano em relação a menores altitudes. Vale salientar também que as áreas de transição com a Mata Atlântica (margem direita da figura) também são mais vegetadas, demonstrando a provável influência do litoral nesses locais. Assim, à medida que as frentes frias entram no continente vão perdendo força, o que reflete nas características da vegetação (SAMPAIO, 1995).

Figura 6: Mapa de altitude (em metros) da Caatinga a partir de imagens SRTM com pontos indicando as 28 estações climatológicas utilizadas. Os tons mais quentes (laranja e vermelho) indicam áreas com maiores altitudes.

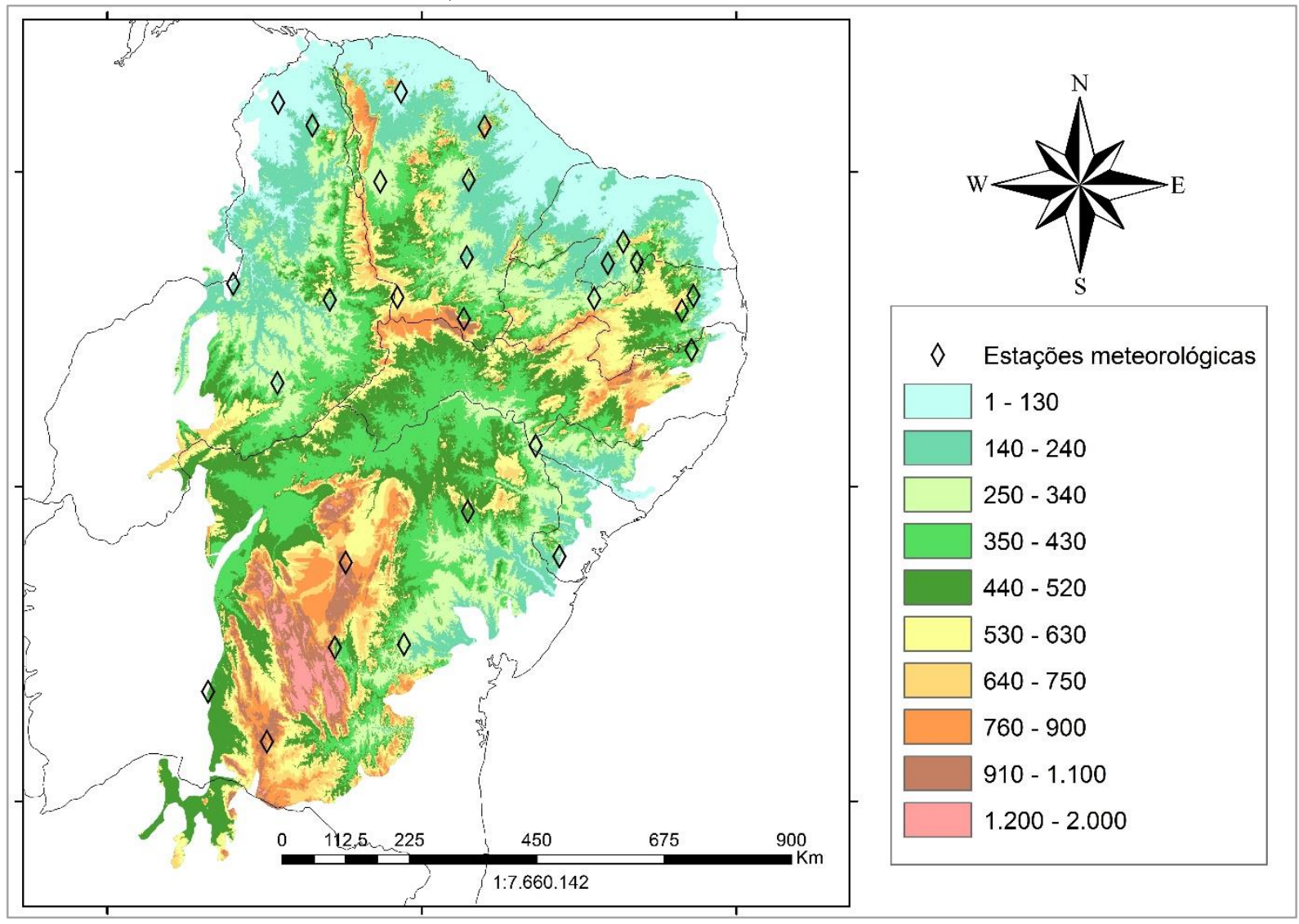

De acordo com os dados da extensão da área verde ao longo do ano de 2010 (Figura 2), é possível observar que no mês de janeiro a cobertura vegetal já possuía uma grande extensão, ou seja, a Caatinga já estava verde. Isso pode ser explicado pela irregularidade do regime de chuvas na Caatinga, o qual pode variar de ano para ano, atrasando ou adiantando alguns meses (SAMPAIO, 1995). O interior da caatinga possui uma estação chuvosa de fevereiro a maio, quando a Zona de Convergência Intertropical (ZCIT) em direção ao sul Sociedade e Território - Natal. Vol. 29, N. 1, p. 183 - 198. Jan./Jun. de 2017 
estaciona no nordeste brasileiro (UVO et al., 1998).

Os valores da área verde mapeada ao longo do ano de 2010 (Figura 2) devem ser observados com ressalva, pois é visível em várias imagens a presença de nuvens no período chuvoso (Figura 3). Esse fato faz com que, na classificação, nuvens tenham sido classificadas como solo exposto, especialmente na região sudeste da Caatinga que apresenta uma cobertura vegetal expressiva no período seco, mas na chuvosa foi classificada como composta por solo exposto (Figura 4). Dessa forma, é provável que a cobertura vegetal na estação chuvosa pode ter uma extensão ainda maior.

O clima é um dos principais fatores que influenciam na paisagem do bioma Caatinga (Andrade-Lima, 1981). Nossos resultados mostraram que a precipitação, como esperado, apresentou relação positiva com a cobertura vegetal e com a temperatura uma relação negativa (Tabela 3). Apesar da grande heterogeneidade de fatores que podem influenciar na dinâmica da vegetação da Caatinga, como características do solo e altitude, o modelo selecionado explicou $40 \%$ da variação dos dados da vegetação, apenas com duas variáveis climáticas.

O entendimento da influência dos padrões climáticos na cobertura vegetal do bioma é muito importante diante das mudanças climáticas globais. Especialmente no bioma Caatinga, que, segundo o PBMC (2013), trata-se do bioma onde é esperada maior alteração no regime de precipitação, com uma significativa redução das chuvas e aumento da temperatura do ar, podendo resultar em profundas alterações no funcionamento desse ecossistema como ocorrências de secas mais intensas e frequentes.

\section{CONCLUSÕES}

O bioma Caatinga apresenta uma grande heterogeneidade (no tempo e no espaço) na dinâmica da vegetação em virtude, principalmente, de fatores climáticos. Nossos resultados demonstraram que a cobertura vegetal apresentou relação positiva com o total de precipitação anual e relação negativa com a temperatura média anual.

A cobertura vegetal apresenta grande mudança ao longo do ano quando comparada com as estações seca e chuvosa. Nesta estação, a paisagem é dominada por uma paisagem verde do rebrotamento das folhas, enquanto que na ausência de chuvas na estação seca, a paisagem muda completamente, influenciando muitos fatores ecológicos, desde eventos populacionais a processos ecossistêmicos.

Sociedade e Território - Natal. Vol. 29, N. 1, p. 183 - 198. Jan./Jun. de 2017 
Com a precipitação e a temperatura explicando $40 \%$ da variação dos dados da vegetação, ressalta-se que o clima é um dos principais fatores que influenciam na paisagem da Caatinga. No entanto, diante da grande heterogeneidade espacial do bioma, outros fatores necessitam ser investigados para se entender melhor essa dinâmica e serem propostas medidas de mitigação de impactos causados pelas mudanças climáticas no funcionamento do ecossistema e para manutenção da biodiversidade.

\section{REFERÊNCIAS}

ANDERSON, L. O.; SHIMABUKURO, Y. E. Classificação Espectro-Temporal de formações vegetais. In: RUDORFF, B. F. T.; SHIMABUKURO, Y. E.; CEBALLOS, J. C. (Org.). . O Sensor MODIS e suas Aplicações Ambientais no Brasil. Parêntese ed. São José dos Campos, SP: [s.n.], 2007. p. 159-171.

ANDRADE-LIMA, D. The Caatingas Dominium. Revista Brasileira de Botânica, v. 4, p. 149-153, 1981.

BARBOSA, H. A.; HUETE, A. R.; BAETHGEN, W. A 20-year study of NDVI variability over the Northeast Region of Brazil. Journal of Arid Environments, v. 67, n. 2, p. 288-307, 2006.

BARNES, W. L.; PAGANO, T. S.; SALOMONSON, V. V. Prelaunch characteristics of the Moderate Resolution Imaging Spectroradiometer (MODIS) on EOS-AM1. IEEE

Transactions on Geoscience and Remote Sensing, v. 36, n. 4, p. 1088-1100, 1998.

BURNHAM, K. P.; ANDERSON, D. R. Multimodel Inference: understanding AIC and BIC in model selection. Sociological Methods \& Research, v. 33, n. 2, p. 261-304, 2004.

CHAMBERS, J. M. Linear Models. In: CHAMBERS, J. M.; HASTIE, T. J. (Org.). . Statistical models in S. [S.1.]: Wadsworth \& Brooks/Cole, 1992. p. 96-138.

ESRI. ArcGIS Desktop Help 9.3. Acesso em: Setembro 2015. Disponível em: $<$ http://webhelp.esri.com>, 2015.

GOOGLE EARTH. Imagens do Nordeste - Brasil. Acesso em: Setembro 2015. Disponível em: < http://www.google.com.br/intl/pt-BR/earth/>, 2015.

HUETE, A. et al. Overview of the radiometric and biophysical performance of the MODIS vegetation indices. Remote Sensing of Environment, v. 83, p. 195-213, 2002.

IBGE. Mapa de Biomas do Brasil. Disponível em:

<http://www.ibge.gov.br/home/presidencia/noticias/21052004biomashtml.shtm>. Acesso em: julho 2017.

INMET/BDMEP. Banco de Dados para Ensino e Pesquisa do Instituto Nacional de Meteorologia. [S.d.]. Disponível em: <http://www.inmet.gov.br/projetos/rede/pesquisa/>.

JENERETTE, G. D.; SCOTT, R. L.; HUETE, A. R. Functional differences between summer Sociedade e Território - Natal. Vol. 29, N. 1, p. 183 - 198. Jan./Jun. de 2017 
and winter season rain assessed with MODIS-derived phenology in a semi-arid region. Journal of Vegetation Science, v. 21, p. 16-30, 2010.

JOHN, R. et al. Predicting plant diversity based on remote sensing products in the semi-arid region of Inner Mongolia. Remote Sensing of Environment, v. 112, p. 2018-2032, 2008.

LEAL, I. R. et al. Changing the Course of Biodiversity Conservation in the Caatinga of Northeastern Brazil. Conservation Biology, v. 19, n. 3, p. 701-706, 2005.

MMA/IBAMA. Monitoramento do Desmatamento nos Biomas Brasileiros por Satélite: Monitoramento do Bioma Caatinga 2002 a 2008. Brasília-DF: Centro de Sensoriamento Remoto-CRS/IBAMA. Disponível em:

<http://siscom.ibama.gov.br/monitorabiomas/caatinga/relatrio_tcnico_caatinga_72.pdf>. 2010

OLIVEIRA, W. M.; CHAVES, I. B.; LIMA, E. R. V. Índices espectrais de vegetação de caatinga em um Neossolo Litólico do semi-árido paraibano. 2009, Natal: [s.n.], 2009. p. 2103-2110.

PBMC. Executive summary: scientific basis of climate change - Contribution from Grupo de Trabalho 1 (GT1, acronym for the Working Group 1) to the Primeiro Relatório de Avaliação Nacional sobre Mudanças Climáticas (RAN1) of the Painel Brasileiro de Mudanças Clim. Rio de Janeiro, Brasil: Universidade Federal do Rio de Janeiro, 2013.

REED, B. C. et al. Measuring phenological variability from satellite imagery. Journal of Vegetation Science, v. 5, n. 5, p. 703-714, 1994.

SAMPAIO, E. V. B. Overview of the Brazilian caatinga. Seasonally Dry Tropical Forests, p. 35-63, 1995.

SHAPIRO, S. S.; WILK, M. B. An Analysis of Variance Test for Normality (Complete Samples). Biometrika, 1965.

SOARES, J. V.; BATISTA, G. T.; SHIMABUKURO, Y. E. Sensor MODIS: Histórico e Descrição. In: RUDORFF, B. F. T.; SHIMABUKURO, Y. E.; CEBALLOS, J. C. (Org.). . O Sensor MODIS e suas Aplicações Ambientais no Brasil. Parêntese ed. São José dos Campos, SP: [s.n.], 2007. p. 3-21.

SULSOFT PROCESSAMENTO DE DADOS. Guia do ENVI em Português. Disponível em: 〈www.envi.com.br>.

UVO, C. B. et al. The Relationships between Tropical Pacific and Atlantic SST and Northeast Brazil Monthly Precipitation. Journal of Climate, v. 11, n. 4, p. 551-562, 1998.

Recebido em Novembro de 2016

Aprovado em Maio de 2017

Publicado em Agosto de 2017

Sociedade e Território - Natal. Vol. 29, N. 1, p. 183 - 198. Jan./Jun. de 2017 